\title{
Excitatory Synaptic Potentials in Kainic Acid-denervated Rat CA1 Pyramidal Neurons
}

\author{
Dennis A. Turner ${ }^{1}$ and Howard V. Wheal ${ }^{2}$ \\ 'Departments of Surgery (Neurosurgery) and Neurobiology, Duke University and Durham Veterans Affairs Medical Center, \\ Durham, North Carolina 27710 and 'Department of Physiology and Pharmacology, University of Southampton, \\ Southampton, SO9 3TU, United Kingdom
}

\begin{abstract}
Intracellular recordings were performed in the CA1 region of the rat hippocampus following an ipsilateral intraventricular injection of kainic acid. Seven days postlesion, graded bursts of up to four action potentials could be evoked by stimulation of the stratum radiatum. The evoked EPSPs underlying these bursts showed a prolonged $10-90 \%$ rise time and half-width compared to control EPSPs, an absence of a significant inhibitory phase, and an increase in magnitude and duration at depolarized resting levels. The evoked EPSPS also exhibited a significant decrease in amplitude and time course in response to D-APV (D-2-amino-5-phosphonovaleric acid; 1-20 $\mu \mathrm{M}$ ), though this effect was variable from cell to cell. The prolonged time course, voltage sensitivity, and response to a selective NMDA antagonist confirmed that the major component of the EPSP in neurons from lesioned slices was mediated by NMDA receptors. The partial denervation of the CA1 area induced by the kainic acid led to both an enhanced NMDA-mediated excitatory phase and a decrease in postsynaptic inhibition, resulting in the pronounced hyperexcitability noted in the lesioned slices.
\end{abstract}

The mechanisms underlying the abnormal excitability within an epileptic region of the cerebral cortex include an exaggerated input-output relationship, often with burst firing; a decrease in inhibition; and relative changes in the local circuits in the cortex (Schwartzkroin and Wyler, 1980). The study of chronic animal models of epilepsy and human brain tissue slices (Lothman and Collins, 1981; Pumain, 1981; Lancaster and Wheal, 1982, 1984; Schwartzkroin et al., 1983; Schwartzkroin and Knowles, 1984; Ashwood et al., 1986; Ashwood and Wheal, 1987; Avoli and Olivier, 1987; Mody and Heinemann, 1987; Franck et al., 1988; Nakajima et al., 1991; Sloviter, 1991) has revealed new physiological mechanisms underlying bursting activity that were not observed in in vitro models generated by acute convulsants, such as penicillin and bicucilline, which block inhibitory processes

\footnotetext{
Received Jan. 28, 1991; revised Apr. 15, 1991; accepted Apr. 17, 1991.

This work was supportcd by the Burroughs-Wcllcome Fund (D.A.T.), the Veterans Affairs Research Service (D.A.T.), the B. S. Turner Foundation (D.A.T.), the Wellcome Trust (H.V.W.), and the Medical Research Council of Great Britain (H.V.W.). We thank Judy Landry for technical assistance and Mary Schlieckert for programming assistance.

Correspondence should be addressed to Dennis A. Turner, M.D., Assistant Professor, Neurosurgery and Neurohiology, Box 3807, Duke I Iniversity Medical Center, Durham, NC 27710.

Copyright (C) 1991 Society for Neuroscience $0270-6474 / 91 / 112786-09 \$ 03.00 / 0$
}

(Dingledine and Gjerstad, 1980; Johnston and Brown, 1981; Wheal et al., 1984). The chronic animal models and abnormal human tissue show less structured and more graded bursting activity than the acute convulsant models. Additionally, neurons in chronic foci exhibit less synchrony, and alterations in inhibition are more focal, often with changes in the local circuitry subserving inhibition (Schwartzkroin and Wyler, 1980; Slovitcr, 1987, 1991). The consequences of denervation and the role of local circuitry changes have been less well characterized in these chronic models, which appear to resemble more closely the recordings from human epileptic cortex. Other models of epilepsy involving the hippocampus, such as the kindling (McNamara et al., 1985; Mody and Heinemann, 1987) and excitability models (Sloviter, 1987, 1991), also exhibit some of the pathological characteristics of the human condition (Schwartzkroin and Wyler, 1980), but in response to electrical stimulation rather than a structural lesion.

The kainic acid (KA) model produced by intracerebroventricular (ICV) injection in the rat has been evaluated by several laboratories (Nadler et al., 1980a,b; Lancaster and Wheal, 1982, 1984; Ashwood et al., 1986; Franck et al., 1988; Turner and Wheal, 1988; Wheal and Turner, 1988; Cornish and Wheal, 1989; Nakajima et al., 1991; Simpson et al., 1991). This model has been previously shown to demonstrate many of the features found in the epileptic human cortex in vitro. These include denervation, loss of inhibition with partial preservation of inhibitory neurons, graded bursts of action potentials, gliosis, and decreased cell number in the focal area of damage (Wheal, 1989). In previous extracellular and intracellular evaluations of this model, the graded burst structure observed on stratum radiatum stimulation has been found to be partially sensitive to selective NMDA antagonists (Ashwood and Wheal, 1987), in contrast to the structured bursts observed following acute blockade inhibition with GABA antagonists such as bicucilline, which exhibit minimal sensitivity to such NMDA antagonists (Wheal et al., 1984). Thus, even in the disinhibited condition (in the presence of bicucilline or penicillin), most of the evoked EPSP in CA1 pyramidal cells appears to remain based on non-NMDA receptor mechanisms, as defined by the use of selective NMDA [such as D-2-amino-5-phosphonovaleric acid (D-APV)] and nonNMDA antagonists [such as 6-cyano-7-dinitroquinoxaline-2,3dione (CNQX); Andreasen et al., 1988].

We have performed a more detailed investigation of the synaptic mechanisms underlying the bursting activity in neurons in vitro partially denervated with KA. A late EPSP component was revealed, often extending the excitatory phase of the evoked 
response to $40-50 \mathrm{msec}$ from the stimulus. This late EPSP was sensitive to NMDA-receptor antagonists that are not normally effective in antagonizing the Schaffer collateral EPSP in C.A1 pyramidal neurons (Koerner and Cotman, 1982; Collingridge et al., 1983; Coan and Collingridge, 1985; Herron et al., 1985; Hablitz and Langmoen, 1986; Andreasen et al., 1988).

Preliminary observations have been published in abstract form (Turner and Wheal, 1988; Wheal and Turner, 1988).

\section{Materials and Methods}

Experimental preparation. Kainic acid lesions were performed on male Wistar rats $(200 \mathrm{gm})$ according to the method of Lancaster and Wheal (1982). This technique involved the stereotaxic injection of $0.5 \mu \mathrm{g}$ of kainic acid into the posterior lateral ventricle over a period of $30 \mathrm{~min}$, performed under barbiturate anesthesia (pentobarbital or Nembutal, 50 $\mathrm{mg} / \mathrm{kg}$, i.p.). Seven days after the lesion, the animals were reanesthetized with halothane, and both hippocampi were removed and sliced (400 $\mu \mathrm{m})$. The dorsal slices from the hippocampus ipsilateral to the lesion were incubated in artificial cerebrospinal fluid (ACSF) for approximately $1 \mathrm{hr}$ before recording and then placed in either a submerged or a subfused in vitro slice chamber. The ACSF was composed of (in $\mathrm{mM}$ ) $\mathrm{NaCl}, 124$; $\mathrm{KCl}, 3.25 ; \mathrm{NaH}_{2} \mathrm{PO}_{4}, 1.25 ; \mathrm{NaHCO}_{3}, 26 ; \mathrm{MgSO}_{4}, 2.0 ; \mathrm{CaCl}_{2}, 2.0$; and D-glucose, 10.

Bipolar, twisted-wire stimulation electrodes were placed in the stratum radiatum (Fig. 1), and glass micropipettes $\left(3 \mathrm{M} \mathrm{K}^{+}\right.$acetate; resistance, $60-90 \mathrm{M} \Omega$ ) were advanced into the stratum pyramidale of the middle CA1 area. Several parameters related to the general health of the CA1 pyramidal cells were intermittently measured throughout the penetration. These parameters included input resistance $\left(R_{N}\right)$, action potential amplitude, membrane resting potential, and time constant $(\tau)$. The amplifier bridge was initially balanced extracellularly and then rebalanced when the penetration was stable. The input resistance values were calculated from the voltage responses to a series of $100-150 \mathrm{msec}$ constant current pulses, injected through the recording electrode, in 0.05 $\mathrm{nA}$ steps between $-0.5 \mathrm{nA}$ and the current requircd to rcach action potential threshold (Ashwood et al., 1986; Andersen et al., 1987; Turner, 1988, 1990). Similar-duration pulses were used to measure the membrane time constant, although these pulses were usually less than -0.2 $\mathrm{nA}$ in amplitude.

Stimuli in the form of $10-40 \mu \mathrm{sec}$ pulses, $5-50 \mu \mathrm{A}$ in magnitude, were delivered at $2 \mathrm{sec}$ intervals to the stratum radiatum of the $\mathrm{CA} 1$ area, evoking a composite EPSP in the CA1 pyramidal neuron (Fig. 1). The evoked EPSPs were averaged and recorded on line in ensembles of 150300 responses. Various manipulations were used to evaluate the EPSPs, including adjustment of the resting membrane potential with a constant hyperpolarizing current, varying the intensity of the synaptic stimulus, and applying an excitatory amino acid receptor (NMDA) antagonist. The NMDA-receptor antagonist D-2-amino-5-phosphonovaleric acid (D-APV; Tocris) was delivered into the bath at concentrations of 1.0 $20 \mu \mathrm{M}$ in ACSF. This solution was usually applied to the bath for a period of approximately $10-20 \mathrm{~min}$ before being washed out with control ACSF.

Data analysis. All data were digitized on line using a high-resolution ( \pm 15 bits) laboratory computer system, at a digitizing rate of either 10 or $20 \mathrm{KHz}$ (Turner and Schlieckert, 1990). These data were stored on either digital tape or optical disk and analyzed using a series of programs for evaluation of intracellular neurophysiological data. The neuron parameters included calculation of input resistance from the slope of the steady-state response to step pulses and determination of the neuron time constant using an exponential regression of the charging or decay portions of the transient.

The evoked synaptic ensembles were analyzed by calculation of an artifact-free average, the time course of the standard deviation (time SD), and histograms of the voltage amplitude of each individual trace, evaluated at the fixed time point of the peak of the mean of the EPSP, similar to reports by Turner (1988) and Sayer et al. $(1989,1990)$. The waveform parameters were evaluated from the ensemble averages and normalized (for comparison between cells) by dividing by the neuron time constant. In order to evaluate the presence of any shunting inhibition, the time constant of the decay of the EPSP was also assessed, beginning at the peak of the potential. Parameters were compared with a Student's $t$ test, for evaluation of differences between means. All values are expressed as mean $\pm \mathrm{SD}$.

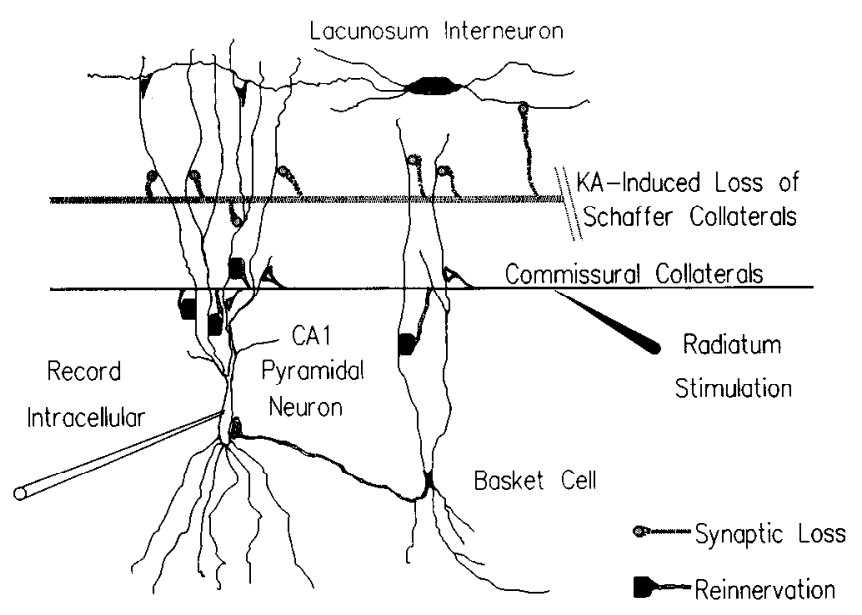

Figure 1. A schematic representation of the CA1 region of the hippocampus following the KA denervation, showing the loss of Schaffer collaterals from the ipsilateral CA3 region (shaded line) and the preservation of the commissural collaterals in the stratum radiatum. The stimulation site in the stratum radiatum is shown involving only the activation of commissural collaterals, at this time point after the lesion. The intracellular recording electrode in a CA1 pyramidal cell is shown, as is the possibility of a new synapse or collateral from the commissural fibers, which is termed reinnervation. The inputs onto the interneurons may also be impaired, as well as the collaterals from the interneurons onto the pyramidal cells, shown with stippled markings. This indicates the hypothesis that, though the individual interneurons may be intact, both the afferents onto the interneurons and the interneuron collaterals themselves may be impaired and unable to participate in the normal dense feedforward and feedback circuitry of the CAl region.

\section{Results}

\section{Intracellular parameters}

Neurons selected from KA-lesioned dorsal hippocampal slices (ipsilateral to the lesion) usually responded with a burst of two or more action potentials in response to stimulation at twicethreshold intensity. A minority of neurons in clearly lesioned slices (as evident by gliosis and a decreased CA1 pyramidal cell layer) exhibited only a single action potential to a suprathreshold stimulus. These neurons were very similar to those recorded from unlesioned slices and thus were not used for this analysis (Andersen et al., 1987; Ashwood and Wheal, 1987; Turner, 1988). A total of 41 neurons fulfilled this bursting criteria as well as allowed a stable and healthy impalement for more than $20 \mathrm{~min}$. The average resting potential for these neurons was 65.1 $\pm 5.4 \mathrm{mV}$ (at the termination of the impalement), the average neuron time constant was $10.3 \pm 2.8 \mathrm{msec}$, and the mean input resistance was $35.0 \pm 14.6 \mathrm{M} \Omega$. The resting potential, input resistance, and time constant of the neurons were measured frequently during the impalement, including before, during, and after the perfusion of drugs. These neurons were extremely difficult to penetrate because of cell loss and gliosis; however, the cells were generally held for 45-60 min once penetrated.

\section{Suprathreshold graded bursts}

Figure 2 shows a typical neuron response to stratum radiatum stimulation, with a progressively graded burst of action potentials to increasing levels of stimulation. At low levels of stimulation, the subthreshold EPSP often was much longer in duration than those recorded from unlesioned slices, as shown in Table 1. The graded bursts closely resembled those recorded in human epileptic cortex (Schwartzkroin et al., 1983; Schwartz- 


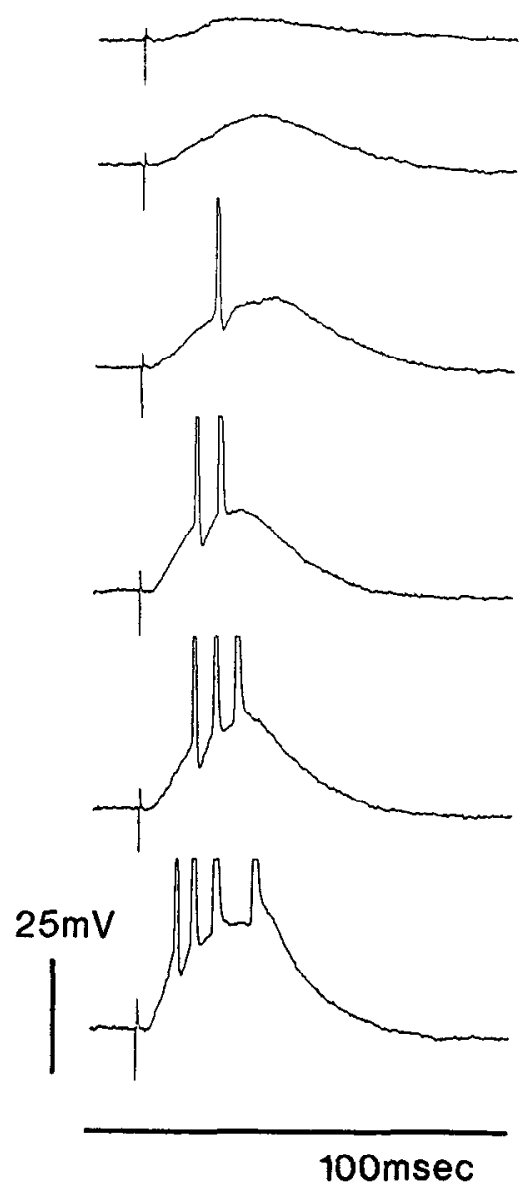

Figure 2. A series of responses to increasing stratum radiatum stimulation, showing the progressive recruitment of a graded burst of action potentials evoked by the EPSP. Up to four action potentials could be evoked in this neuron, demonstrating the abnormal hyperexcitability. The peaks of the action potentials were truncated to show the comparison to the subthreshold EPSP.

kroin and Knowles, 1984; Avoli and Olivier, 1987). These graded bursts are significantly different from the structured bursts associated with acute loss of inhibitory drive, which also demonstrate an associated afterhyperpolarization (Dingledine and Gjerstad, 1980; Johnston and Brown, 1981; Wheal et al., 1984). The presence of multiple spikes also demonstrates the relative loss of inhibition in this typical cell, with neither an effective hyperpolarization nor a shunting effect apparent following the peak of the synaptic potential.

The order of analysis after achieving a stable impalement included assessing the range of synaptic potentials that could be evoked in the postsynaptic neuron, calculating an initial input resistance, and then evoking a series of synaptic potentials that bordered on threshold for spike generation. The latter were averaged on-line, and the amplitude of the stimulus intensity was adjusted as required to achieve this level of evoked response. After collecting an ensemble of synaptic stimulation data, the evoked EPSPs were analyzed during a range of stimulus intensities and membrane potentials before being returned to control levels.

\section{Characteristics of subthreshold EPSPS}

A series of subthreshold responses to stratum radiatum stimulation is shown in Figure 3 . Figure $3 A$ demonstrates a highly
Table 1. Subthreshold EPSP parameters

\begin{tabular}{lll} 
EPSP parameter & $\begin{array}{l}\text { Lesioned } \\
\text { EPSPs } \\
(n=11)\end{array}$ & $\begin{array}{l}\text { Control } \\
\text { EPSPs } \\
(n=10)\end{array}$ \\
\hline Peak amplitude $(\mathrm{mV})$ & $1.57 \pm 0.98$ & $1.51 \pm 0.40$ \\
$10-90 \%$ rise time $(\mathrm{msec})$ & $7.89 \pm 3.25^{*}$ & $3.33 \pm 2.10$ \\
$10-90 \%$ rise time $(\tau)$ & $0.77 \pm 0.33^{*}$ & $0.22 \pm 0.19$ \\
Half-width (msec) & $31.2 \pm 10.7^{*}$ & $16.6 \pm 6.58$ \\
Half-width $(\tau)$ & $3.01 \pm 1.03^{*}$ & $1.00 \pm 0.53$
\end{tabular}

The EPSP data from lesioned cells represent a subset of the present data, following stratum radiatum stimulation. The control values are from a normal CA1 population in rats, studicd with similar techniques. Both groups represent responses that are less than $2.5 \mathrm{mV}$ in peak amplitude. The waveform parameters were normalized by the somatic time constant for each cell. The means were compared with a two-way Student's $t$ test, and the resulting probability is indicated $\left({ }^{*} p<0.001\right)$.

variable EPSP morphology between individual responses, with scveral traccs showing an extended depolarization, cxtending to greater than $100 \mathrm{msec}$ after the stimulus artifact, as seen in traces 2 and 4 (from the top). There was also one possible failure of response (trace 1), which is unusual for this amplitude of EPSP. The $10-90 \%$ rise time $(14.3 \mathrm{msec})$ and half-width $(70.8 \mathrm{msec})$ of this ensemble were significantly prolonged compared to previous reports of EPSPs in CA1 pyramidal cells (Andersen et al., 1987; Turner, 1988; Sayer et al., 1989, 1990). For comparison to the data from lesioned slices, a control series of small EPSPs (D. A. Turner, unpublished observations) was selected from potentials evoked in response to selective stratum radiatum microstimulation in rat hippocampal slices; a subset of these EPSPs (also less than $2.5 \mathrm{mV}$ peak amplitude) is shown in Table 1. The waveform values for the EPSPs in CAl pyramidal neurons from lesioned slices showed a significant prolongation in comparison to the parameters from the control EPSPs (Andersen et al., 1987; Turner, 1990). The control EPSP values (also shown in Fig. 4) were similar to previously published waveform parameter values for stratum radiatum EPSPs in CA1 pyramidal cells (Andersen et al., 1987; Turner, 1988; Sayer et al., 1990).

The log decay trace in Figure $3 B$ shows the decay of potential after the peak of the response, which is linear and possesses a longer time constant than the neuron time constant (decay $\tau=$ $53.8 \mathrm{msec}$ vs. neuron $\tau=13.9 \mathrm{msec}$ ). This finding of a longer decay $\tau$ suggests that very little postsynaptic inhibition is present, either of the shunting or of the hyperpolarizing type (Turner, 1990), and that the excitatory drive is extremely prolonged. The individual EPSP responses occasionally showed a fractionation into components, with short, faster-rising events intermixed with longer, slower components. This fluctuation between EPSPs with different time components suggests the intermittent presence of two different types of postsynaptic potentials (Dale and Roberts, 1985). The delineation between an early response and the late response was also similar to intermixed fast and slow EPSP responses in neurons from the spinal cord (Mayer and Westbrook, 1987) and neocortex (Thomson et al., 1988). The histogram in Figure $3 C$ shows the variability of the signal in comparison to the background noise, with some overlap of the two histograms, suggesting the occurrence of failures.

\section{Waveform parameter comparison}

A shape-index plot of the evoked EPSPs from lesioned and control slices is shown in Figure 4. The potentials from the lesioned slices clustered to the right and above the control data, 
A.

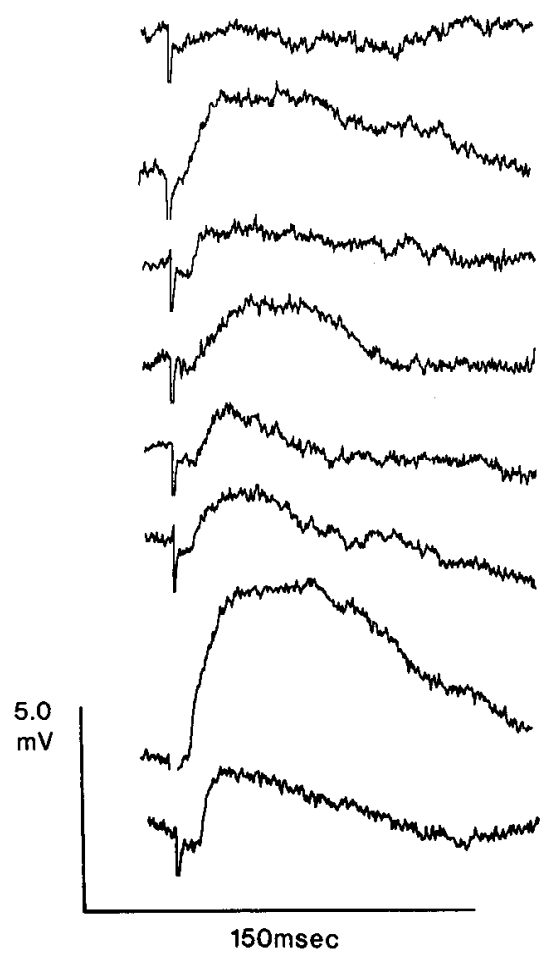

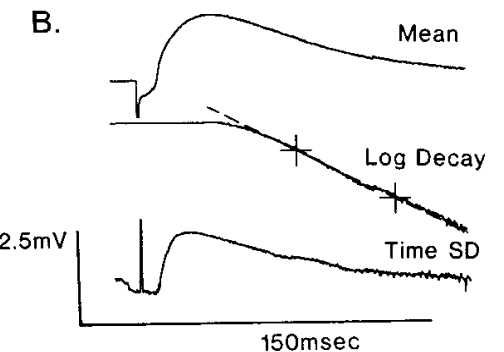

C.

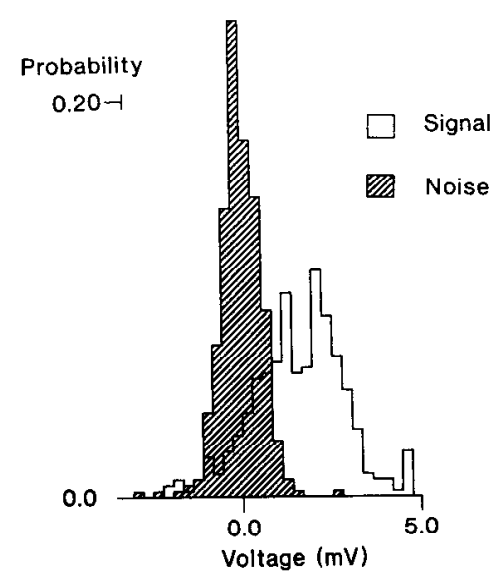

Figure 3. A, A series of evoked EPSP responses following stratum radiatum stimulation is shown. The magnitudes of these responses vary from less than $1 \mathrm{mV}$ to greater than $5 \mathrm{mV}$, and the time course is also highly variable. Note also the lack of any hyperpolarizing components and the occasional absence of a response (top trace). $B$, These traces show the mean, the log decay from the peak of the EPSP, and the time course of the standard deviation (time SD). The time constant of the decay from the peak was significantly longer than that observed from the decay response to a direct current transient $(53.8 \mathrm{msec} / \mathrm{vs}$. $13.9 \mathrm{msec}$ ). The waveform parameters of the mean showed a $10-90 \%$ rise time of $14.3 \mathrm{msec}$ and a half-width of 70.8 msec. $C$, The histogram shows the prestimulus fluctuations in the baseline, attributable to both synaptic noise and electrode noise, and the peak of the signal for each trial of the ensemble. The bin size in the histogram is $0.26 \mathrm{mV}$, which is one-half of the noise SD. The signal peak amplitude was $1.72 \pm 1.22$ $\mathrm{mV}$, compared to the noise amplitude of $-0.09 \pm 0.52 \mathrm{mV}$. with signiticantly longer rise times and half-widths on average than small stratum radiatum EPSPs in rat CA1 pyramidal cells (Table 1; Andersen et al., 1987; Turner, 1988; Saycr ct al., 1989, 1990). Since many of the observed KA EPSP values fell outside of the most distal rise time and half-width values, this may indicate either a different time course of the late EPSP at the dendritic origin of the potential or alterations in the electrotonic dendritic structure of denervated neurons (Turner, 1988).

\section{Voltage and D-APV sensitivity of EPSPS}

The voltage sensitivity of the evoked EPSP was assessed by applying a constant hyperpolarizing current to the neuron. Figure 5 shows one EPSP ensemble at three different resting membrane potentials $(-60,-70$, and $-80 \mathrm{mV})$, both during $20 \mu \mathrm{M}$ D-APV and after recovery, recorded from a surface slice. The waveform parameters of the EPSPs demonstrated a pronounced difference before and after the D-APV, particularly in the halfwidth: at $-60 \mathrm{mV}$ in D-APV, the rise time was $5.3 \mathrm{msec}$ and the half-width was $19.4 \mathrm{msec}$, while at $-60 \mathrm{mV}$, during the recovery the rise time increased to $6.4 \mathrm{msec}$ and the half-width lengthened to $33.8 \mathrm{msec}$. There was also a pronounced effect of the resting membrane potential, with shorter responses at hyperpolarized levels, particularly after the recovery from the D-APV. The EPSP waveform values at the hyperpolarized levels and during the D-APV were similar to the parameters of control EPSPs recorded in the CA1 region (Table 1; Turner, 1988, 1990). The subtraction traces shown in Figure $5 B$ demonstrate directly the effect of D-APV in this neuron, with the return of a long, late EPSP component during recovery from the D-APV. Thus, the phase of the EPSP that is sensitive to a selective NMDA antagonist appears to correspond in time course to the late EPSP component shown in Figure $3 A$. Figure $5 D$ graphs the changes observed in this cell, both during and after the D-APV and also as a function of resting membrane potential. The main effect of both perturbations was a change in the half-width, which was prolonged at depolarizing resting potentials and in the recovery conditions.

Figure 6 demonstrates another neuron and the effect of $20 \mu \mathrm{M}$

$$
\text { Shape Index Plot }
$$

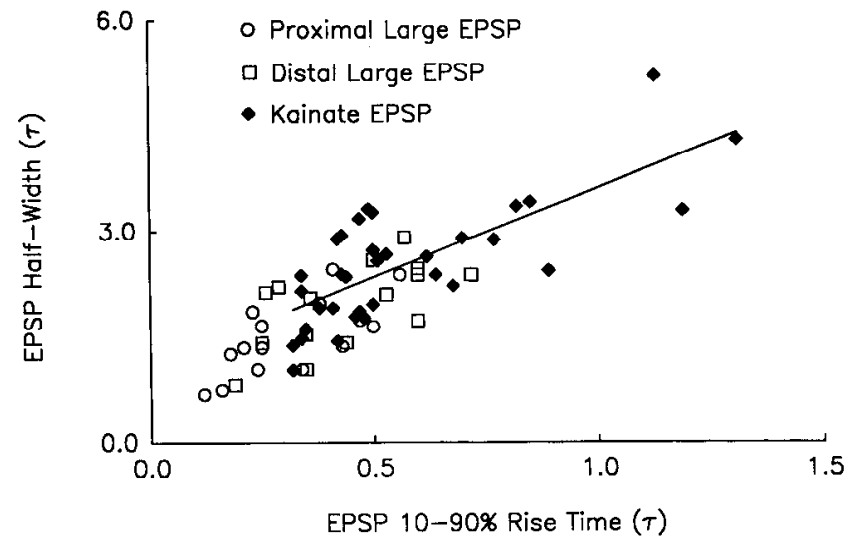

Figure 4. A shape-index plot of normalized 10-90\% rise time versus normalized half-width, comparing previous results for EPSPs evoked from stratum radiatum stimulation in unlesioned slices (circles and squares) to parameters of evoked EPSPs in the KA-treated slices (diamonds). Most of the responses from lesioned slices lie beyond the most distal response from unlesioned neurons, suggesting the addition of a longer EPSP component in the lesioned cells for the group of EPSPs as a whole. 

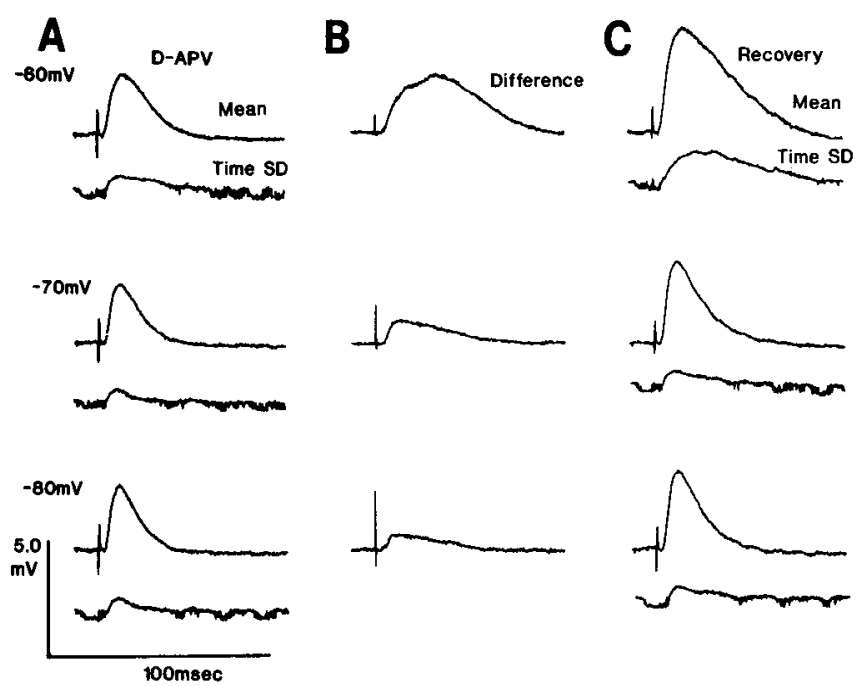

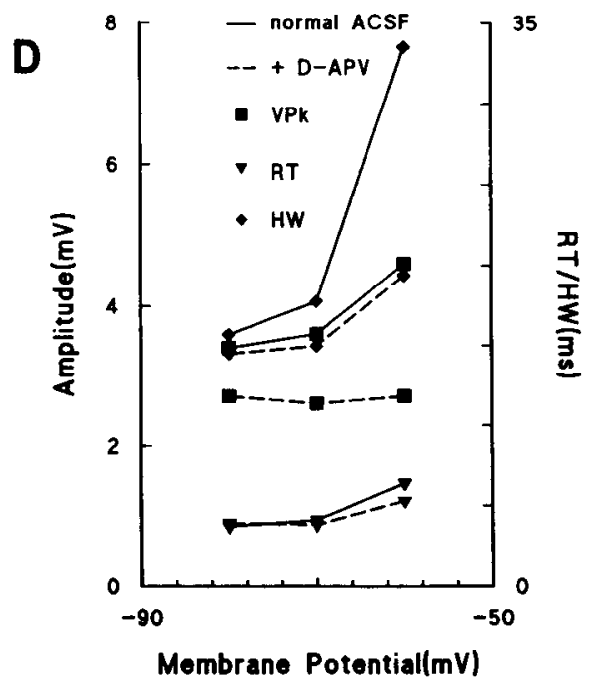

Figure 5. An evoked EPSP in a lesioned slice is shown in response to both D-APV $(20 \mu \mathrm{M})$ and at three different resting membrane potentials. The mean and time SD are shown for these different conditions, as well as subtractions between the responses during and after the D-APV application. $A$, An evoked stratum radiatum EPSP is shown during the D-APV application at resting membrane potentials of $-60,-70$, and -80 $\mathrm{mV}$. There is only a small difference between the different membrane potentials during the D-APV, and there is considerable residual EPSP present in this example. $B$, These three traces show the difference between the responses in the D-APV and during the recovery periods, at three different membrane potentials. The largest difference is noted at the most depolarized membrane potential, indicating that the D-APV antagonized mainly the voltage-sensitive component, which prolonged the EPSP beyond the peak observed in the D-APV solution. $C$, These traces demonstrate the recovery from the D-APV application, with a clear voltage-sensitive component noted at $-60 \mathrm{mV}$. However, there is also a change in the EPSP at even the more hyperpolarized levels following the D-APV, suggesting an effect on even the faster EPSP phase by the NMDA antagonist, though small. $D$, This summary chart shows the changes in the peak magnitude and waveform parameters of the EPSP in $A-C$ as functions of both $\mathrm{D}-\mathrm{APV}$ exposure and resting membrane potential. The solid lines represent the responses in normal solution, with the most pronounced difference between the membrane potentials noted in the half-width (shown by diamonds). The broken lines show the D-APV response, with a dampened voltage sensitivity. There is only a small change in the actual peak voltage (shown by squares) in this example, decreasing from $3.5 \mathrm{mV}$ at -80 $\mathrm{mV}$ resting potential in the normal solution to $2.4 \mathrm{mV}$ in the D-APV at $-80 \mathrm{mV}$ resting potential. Thus, the two manipulations of D-APV and hyperpolarization both decreased the peak and particularly the half-width of the EPSP, in an additive manner.

D-APV on the EPSP, recorded from a submerged slice. In this example, with the same dose of D-APV as in Figure 5, there was only a minimal residual EPSP component remaining in the D-APV, with essentially complete recovery of the EPSP in the return to control conditions. The EPSP average shown in Figure 6 had a peak amplitude of $11.0 \mathrm{mV}$, a rise time of $5.1 \mathrm{msec}$, and a half-width of $35.1 \mathrm{msec}(n=150$ responses). Below the mean and time SD are shown the histograms of the background noise and the evoked EPSP signal, demonstrating excellent separation of the EPSP values from the noise. Figure $6 B$ shows the response after $10 \mathrm{~min}$ in $20 \mu \mathrm{M} \mathrm{D}$-APV, with a near-complete block of the EPSP by the antagonist, to a residual peak amplitude of only $0.1 \mathrm{mV}$, a rise time of $2.4 \mathrm{msec}$, and a half-width of 8.2

\begin{tabular}{llll}
\hline Table 2. Response of evoked EPSPs to D-APV & \\
& Control & D-APV & Recovery \\
\hline Peak amplitude $(\mathrm{mV})$ & $7.10 \pm 4.28$ & $1.18 \pm 1.17^{* *}$ & $5.41 \pm 4.88$ \\
$10-90 \%$ rise time (msec) & $5.30 \pm 2.22$ & $3.14 \pm 1.21^{*}$ & $5.45 \pm 2.78$ \\
$10-90 \%$ rise time $(\tau)$ & $0.50 \pm 0.16$ & $0.32 \pm 0.17^{*}$ & $0.51 \pm 0.22$ \\
Half-width (msec) & $24.1 \pm 10.6$ & $13.0 \pm 5.13^{* *}$ & $26.9 \pm 17.0$ \\
Half-width $(\tau)$ & $2.07 \pm 0.66$ & $1.25 \pm 0.52^{* *}$ & $2.46 \pm 1.21$
\end{tabular}

$\overline{\text { A range of doses of D-APV }(1-20 \mu \mathrm{M}) \text { resulted in a significant diminution of the }}$ amplitude and duration of the evoked EPSP responses ( $n=13$ cells with recovery). The significance values shown indicate the probability derived using a two-tailed Student's $t$ test $\left({ }^{*} p<0.01 ;{ }^{* *} p<0.001\right)$. The recovery values were not significantly different from the control values in all cases. Values for two ranges of doses (1-5 $\mu \mathrm{M}$ and $10-20 \mu \mathrm{M}$ ) were also not significantly different from the overall values. msec. Figure $6 C$ shows the recovery of the EPSP 20 min later, in response to the same orthodromic stimulus. The histograms below the traces also show excellent recovery of the histogram shape demonstrated in the control situation. The recovery mean exhibited a peak amplitude of $11.5 \mathrm{mV}$, a rise time of $4.3 \mathrm{msec}$, and a half-width of $27.7 \mathrm{msec}$, all values similar to the original EPSP.

A total of 13 cells demonstrated recovery from the effects of the antagonist, at doses ranging from $1 \mu \mathrm{M}$ to $20 \mu \mathrm{M}$ in the ACSF. An additional three cells showed a similar response but either did not recover following the D-APV or were impaled during the D-APV infusion and thus were not included in the analysis (including the response shown in Fig. 5). At these concentrations, no consistent effects of D-APV were seen on either the input resistance or the membrane time constant of the cells. The results were also split into two groups of dosages: less than $10 \mu \mathrm{M}$ and greater than or equal to $10 \mu \mathrm{M}$. The results were quantitatively similar to that shown in Table 2 for these two dosage ranges (not shown). Table 2 shows the overall results for neurons that exhibited recovery of the EPSP, though the effect in some cases was not as complete as that demonstrated in Figure 6. The average blockade of the evoked EPSP was to a level approximately $17 \%$ (range, $1-25 \%$ ) of that of the control value, and both the $10-90 \%$ rise time and half-width were substantially reduced. Some EPSP ensembles appeared to be completely composed of NMDA-mediated events, whereas others exhibited only a partial non-NMDA contribution, as shown in Figure 5. This cell-to-cell heterogeneity was also noted with the 


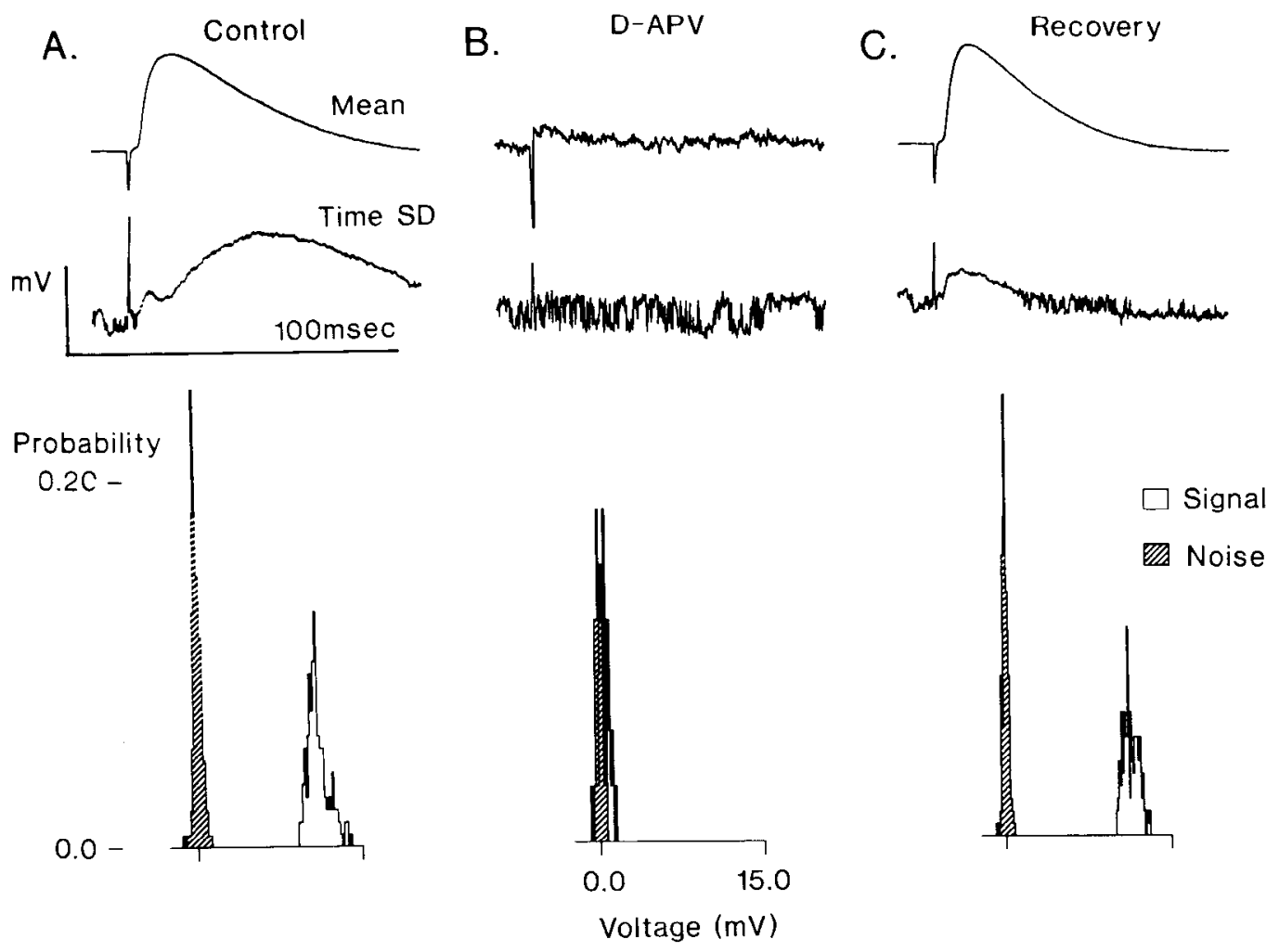

Figure 6. A, Another evoked EPSP response from a lesioned slice, showing the mean, time SD, and amplitude histogram of the peak voltage value from an ensemble $(n=150)$. The waveform parameters of the mean were as follows: peak, $11.0 \mathrm{mV}$; rise time, $5.1 \mathrm{msec}$; half-width, 35.1 msec. The time SD showed a delayed time course of fluctuation for this ensemble. The time SD trace is shown at $2 \mathrm{mV}$ for the scale marker, while the mean is scaled to $5 \mathrm{mV} . B$, The evoked response to the same stimulus intensity as in $A$, but 5 min after the bath application of $20 \mu \mathrm{M}$ D-APV. The response rapidly decreased on exposure to the agent, reaching a stable average with the following parameters: peak, $0.1 \mathrm{mV}$; rise time, 2.4 msec; half-width, $8.2 \mathrm{msec}$. Note the overlap of signal and background noise histograms. Both the mean and time SD are shown at an expanded scale of $2 \mathrm{mV}$. C, The traces to the right show the responses $20 \mathrm{~min}$ after the washout from the D-APV, with essentially a full recovery from the effects of the agent. The parameters for this ensemble were as follows: peak, $11.5 \mathrm{mV}$; rise time, $4.3 \mathrm{msec}$; half-width, $27.7 \mathrm{msec}$. The full cycle as repeated again after this, with an essentially similar response to the D-APV noted and again full reversibility. The mean is shown at a scale of 5 $\mathrm{mV}$.

non-NMDA antagonist CNQX in a recent preliminary report on similar neurons (Simpson et al., 1991), indicating that the non-NMDA aspect of the EPSP remains sensitive to CNQX but that there also may be a variable ratio of the receptor subtypes. The sensitivity to NMDA antagonists is markedly different than observed in either unlesioned slices or following acute blockade of inhibition (Koerner and Cotman, 1982; Collingridge et al., 1983; Wheal et al., 1984; Coan and Collingridge, 1985; Herron et al., 1985; Hablitz and Langmoen, 1986; Andreasen et al., 1988).

\section{Discussion}

\section{Characteristics of EPSPS following the KA denervation}

The prolonged time course, voltage sensitivity, and response to low doses of a selective NMDA antagonist all suggest that the evoked EPSPs recorded from many surviving CA1 pyramidal cells in the KA-lesioned hippocampus are predominantly mediated by NMDA receptors (Herron et al., 1985; Dingledine et al., 1986; Hablitz and Langmoen, 1986; Andreasen et al., 1988; Forsythe and Westbrook, 1988; Thomson et al., 1988). The waveform parameters, when compared to the control EPSP values recorded from unlesioned slices, showed a consistent prolongation over the normal values. The time course of the voltage-sensitive component of the EPSP was also similar to that measured in unlesioned hippocampal preparations in which the EPSPs were evoked in media containing no extracellular $\mathrm{Mg}^{2+}$, to allow full expression of the NMDA responses (Coan and Collingridge, 1985). Likewise, the graded bursts recorded from the lesioned slices (Fig. 2; Franck et al., 1988) were significantly different from the structured bursts associated with acute loss of postsynaptic inhibition (Dingledine and Gjerstad, 1980; Wheal et al., 1984), suggesting that more features are present than the loss of the inhibitory drive alone. Thus, the present findings are not compatible with the loss of inhibitory drive as the sole mechanism leading to hyperexcitability, and changes in the predominant receptor mechanisms underlying the EPSP (nonNMDA and NMDA) appear to have a significant role in the hyperexcitability.

The time course of the alteration in glutamate-receptor expression with the denervation is not fully known, particularly in the first few days after the denervation and after several weeks. Thus, the present findings may be a phase in response to the denervation, and some degree of recovery may occur over several weeks (Cavalheiro ct al., 1982), as suggested by anatomical studies of denervation and plasticity (Nadler et al., 1980a,b; Cotman and Neito-Sampedro, 1984; Phelps et al., 1991). Though paired-pulse facilitation (as a result of failure of early pairedpulse inhibition) continued in vivo for weeks after a KA lesion 
(Cornish and Wheal, 1989), other groups studying the KA model have suggested an eventual partial recovery from the hyperexcitability associated with the KA lesion (Franck et al., 1988).

Following the loss of the CA3 pyramidal cells and their Schaffer collaterals (schematically shown in Fig. 1), deafferentation and reactive synaptogenesis occur on the CA1 dendrites (Nadler et al., 1980a,b; Phelps et al., 1991; Wheal, 1990). In response to degenerating terminals (as the destroyed afferents die back), there are probably associated changes in the morphology of the dendrites and dendritic spines, as shown previously with bilateral KA lesions (Nadler et al., 1980a,b) and perforant path lesions (Cotman and Neito-Sampedro, 1984). These morphological changes may be associated with an altered physiological response. At some point in the evolution of the denervation, the formation of new synapses on modified spines or on the shafts of the dendrites is likely to occur; these new synapses might incorporate a different ratio of non-NMDA to NMDA receptors than is present normally. The recovery of the lesion might therefore depend upon both the maturation of the receptors at the excitatory synapses to a non-NMDA type (possibly accompanied by spine restoration) as well as the partial reconstitution of inhibitory circuitry.

Candidate afferents involved in the reinnervation of the CA1 synapses include commissural and alvear pathways; however, there is also indirect evidence in favor of CA1-CA1 recurrent excitatory terminals, which may be enhanced after the denervation (Christian and Dudek, 1988), though a recent pairedrecording study in the KA-lesioncd CA1 region did not find such recurrent excitatory collaterals (Nakajima et al., 1991). EPSPs recorded from CA3 pyramidal cells following recurrent activation were found to be both slow and voltage sensitive (Miles and Wong, 1986). Furthermore, preliminary investigations of EPSPs evoked by activation of local excitatory connections between CA1 neurons suggest that they are mediated in part by NMDA receptors (Radpour and Thomson, 1991). Thus, one possibility is that recurrent excitatory connections usually exist in the CA1 hippocampal field, but are normally suppressed by the dense feedforward inhibition (Turner, 1990). Under suitable conditions, such as the partial denervation and loss of inhibition after the KA lesion, recurrent excitatory collaterals may be expressed more favorably than other existing afferents, leading to the prolonged EPSPs noted in the present report. However, there is no direct evidence as yet for this possibility in the CA1 rcgion (Nakajima ct al., 1991).

\section{Alterations in electrotonic integration}

The prolonged EPSP clearly resulted in increased overall excitation, with the development of the graded burst response as shown in Figure 3 at only moderate levels of stimulation. This powerful excitatory drive, in concert with the loss of postsynaptic inhibition (Ashwood et al., 1986; Franck et al., 1988; Cornish and Wheal, 1989; Wheal, 1989), suggests a marked switch in the overall input-output relationship for the CA1 neuron toward hyperexcitability. One might also suggest that the loss of the Schaffer collaterals removes the excitatory drive to the interneurons that are responsible for feedforward inhibition in the CA1 area (Turner, 1990). This would result in the loss of both the early $\mathrm{GABA}_{\mathrm{A}}$ chloride-mediated IPSP as well as the late $\mathrm{GABA}_{\mathrm{B}}-\mathrm{K}^{+}$-mediated hyperpolarization (Ashwood ct al., 1986). In functional terms, the carly shunting inhibition is thought to control the somatic conductance and thus the output of the cell, while the late dendritic $\mathrm{K}^{+}$hyperpolarizing response would regulate the level of synaptic excitation in the dendrites (Wheal, 1989). Thus, the loss of the latter $\mathrm{K}^{+}$-mediated hyperpolarizing response may be sufficient to enable small synaptic depolarizations in the dendrites to summate and become more apparent at the soma. Loss of these and other $\mathrm{K}^{+}$conductances may also contribute to the trend of increased neuron input resistance and decreased electrotonic length values after the KA lesion (Franck et al., 1988; Wheal, 1989). However, further studies on the dendritic location of synapses and the electrotonic length of neurons in lesioned slices will be required before the functional aspects involved with integration of the excitatory and inhibitory synapses can be resolved in the CA1 pyramidal cell.

\section{Relevance to human epilepsy and other animal models}

The KA lesion has been suggested to exhibit many of the characteristics of the human temporal lobe epileptic lesion, including neuron damage and loss, relative preservation of inhibitory neurons without demonstrable postsynaptic inhibition, and the presence of graded bursts (Nadler et al., 1980a,b; Lothman and Collins, 1981; Cavalheiro et al., 1982; Schwartzkroin and Knowles, 1984; Dichter and Ayala, 1987; Franck et al., 1988; Wheal, 1989). The present data indicate that the sensitivity of the graded bursts to NMDA antagonists may also be another similarity (Avoli and Olivier, 1987). These findings imply that both abnormalities within single neurons (such as changes in the expression of membrane channels) as well as local circuit alterations may contribute to the hyperexcitability of cells, consistent with previous hypotheses concerning mechanisms underlying epileptiform abnormalities (Schwartzkroin and Wyler, 1980; Dichter and Ayala, 1987).

The current dose of KA $(0.5 \mu \mathrm{g})$ is a moderate dose in terms of leading to epileptic phenomena (Nadler et al., 1980a,b; Cavalheiro et al., 1982; Lancaster and Wheal, 1982), and the comparison to human epileptic foci may be a matter of severity and degree of hippocampal damage. At this moderate dose, some recovery from the effects of the $\mathrm{CA} 3$ lesion and denervation appears to occur; the behavioral effects over time as a function of dose likewise ameliorate, in terms of electrographic and clinical seizure occurrence. Similar recovery has also been reported in other chronic models of epilepsy, including the tetanus toxin model (Jeffreys, 1989). In many cases of posttraumatic human epilepsy, the incidence and frequency of seizures likewise decrease with time after an insult, indicating that recovery in the CNS is likely to occur. However, in many hippocampal foci in humans, seizure production appears to be stable as a function of time. Thus, while the use of the KA model has enabled us to unravel several of the major mechanisms that underlie epileptiform activity present in human epileptic foci, further studies are required on the processes that may influence or control the time course of recovery. For example, what influence might the reciprocal synaptic connections with the entorhinal cortex or septum have on epileptiform activity in the abnormal hippocampus?

In conclusion, we have recorded voltage-sensitive EPSPs from partially denervated CA 1 hippocampal pyramidal cells, in the presence of normal levels of $\mathrm{Mg}^{2+}(2 \mathrm{mM})$. These evoked potentials were selectively antagonized by D-APV, further suggesting that they were mediated by the activation of NMDA receptors. The EPSPs had a slower time course than control EPSPs recorded from similar cells in unlesioned slices. It is not yet understood how this change in receptor type may be brought 
about; however, we are investigating the possibility that it may be a result of synaptogenesis following the partial denervation of the CAl pyramidal cells.

\section{References}

Andersen P, Storm J, Wheal HV (1987) Thresholds of action potentials evoked by synapses of the dendrites of pyramidal neurons in the rat hippocampus in vitro. J Physiol (Lond) 383:509-526.

Andreasen M, Lambert JDC, Jensen MS (1988) Direct demonstrations of an $\mathrm{N}$-methyl-D-aspartate receptor mediated component of excitatory synaptic transmission in area $\mathrm{CAl}$ of the rat hippocampus. Neurosci Lett 93:61-66.

Ashwood TJ, Wheal HV (1987) The expression of $N$-methyl-D-aspartate-receptor mediated component during epileptiform synaptic activity in the hippocampus. Br J Pharmacol 91:815-822.

Ashwood TJ, Iancaster B, Wheal HV (1986) Intracellular electrophysiology of CA1 pyramidal neurones in slices of the kainic acid lesioned hippocampus of the rat. Exp Brain Res 62:189-198.

$\Lambda$ voli M, Olivier A (1987) Bursting in human epileptogenic neocortex is depressed by an $N$-methyl-D-aspartate antagonist. Neurosci Lett 76:249-254.

Cavalheiro EA, Riche DA, Le Gal La Salle G (1982) Long-term effects of intrahippocampal kainic acid injection in rats: a method for inducing spontaneous recurrent seizures. Electroencephalogr Clin Neurophysiol 53:581-589.

Christian EP, Dudek FE (1988) Electrophysiological evidence from glutamate microapplicants for local excitatory circuits in the CA1 area of rat hippocampal slices. J Neurophysiol 59:110-123.

Coan EJ, Collingridge GL (1985) Magnesium ions block an $N$-methylD-aspartate receptor-mediated component of synaptic transmission in rat hippocampus. Neurosci Lett 53:21-26.

Collingridge GL, Kehl SJ, McLennan H (1983) Excitatory amino acids in synaptic transmission in the Schaffer collateral-commissural path way of the rat hippocampus. J Physiol (Lond) 334:33-46.

Cornish SM, Wheal HV (1989) Long-term loss of paired pulse inhibition in the kainic acid-lesioned hippocampus of the rat. Neuroscience 28:563-571.

Cotman CW, Neito-Sampedro M (1984) Cell biology of synaptic plasticity. Science 225:1287-1294.

Dale N, Roberts A (1985) Dual-component amino-acid-mediated synaptic potentials: excitatory drive for swimming in Xenopus embryos. J Physiol (Lond) 363:35-59.

Dichter M, Ayala GF (1987) Cellular mechanisms of epilepsy: a status report. Science 237:157-164.

Dingledine R, Gjerstad L (1980) Reduced inhibition during epileptiform activity in the in vitro hippocampal slice. J Physiol (Lond) 305:297-313.

Dingledine R, Hynes MA, King GL (1986) Involvement of $N$-methyl$\mathrm{D}$-aspartate receptors in epileptiform bursting in the rat hippocampal slice. J Physiol (Lond) 380:175-189.

Forsythe ID, Westbrook GL (1988) Slow excitatory postsynaptic currents mediated by $N$-methyl-D-aspartate receptors on cultured mouse central neurones. J Physiol (Lond) 396:515-533.

Franck J, Kunkel DD, Baskin DG, Schwartzkroin PA (1988) Inhibition in kainate-lesioned hyperexcitable hippocampi: physiological, autoradiographic and immunocytochemical observations. J Neurosci 8:1991-2002.

Hablitz JJ, Langmoen IA (1986) NMDA receptor antagonists reduce synaptic excitation in the hippocampus. J Neurosci 6:102-106.

Herron CE, Lester RAJ, Coan EJ, Collingridge GL (1985) Intracellular demonstration of an $N$-methyl-D-aspartatc recptor mediated component of synaptic transmission in the rat hippocampus. Neurosci Lett 60:19-23.

Jeffreys JGR (1989) Chronic epileptic foci in vitro in hippocampal slices from rats with the tetanus toxin epileptic syndrome. J Neurophysiol 62:458-468.

Johnston D, Brown TH (1981) Giant synaptic potential hypothesis for epileptiform activity. Science 211:294-297.

Koerner JF, Cotman CW (1982) Response of Schaffer collateral--CA1 pyramidal cell synapses of the hippocampus to analogues of acidic amino acids. Brain Res 251:105-115.

Lancaster B, Wheal HV (1982) A comparative histological and electrophysiological study of some neurotoxins in the rat hippocampus. J Comp Neurol 211:105-114.
Lancaster B, Wheal HV (1984) Chronic failure of inhibition of the CA1 area of the hippocampus following kainic acid lesions of the CA3/4 area. Brain Res 295:317-324.

Lothman EW, Collins RC (1981) Kainic acid induced limbic seizures: metabolic, behavioral, electroencephalographic and neuropathological correlates. Brain Res 218:299-318.

Mayer ML, Westbrook GL (1987) The physiology of excitatory amino acids in the vertebrate nervous system. Prog Neurobiol 28:197-276.

McNamara JO, Bonhaus DW, Shin C, Crain BJ, Gellman RL, Giacchino JL (1985) The kindling model of epilepsy: a critical review. Crit Rev Clin Neurobiol 1:341-391.

Miles R, Wong RKS (1986) Excitatory synaptic interactions between CA3 neurones in the guinea pig hippocampus. J Physiol (Lond) 373: $397-418$.

Mody I, Heinemann U (1987) NMDA receptors of dentate gyrus granule cells participate in synaptic transmission following kindling. Nature 326:701-704.

Nadler JV, Perry BW, Cotman CW (1980a) Selective reinnervation of hippocampal area $\mathrm{CA} 1$ and the fascia dentate after destruction of CA3-CA4 afferents with kainic acid. Brain Res 182:1-9.

Nadler JV, Perry BW, Gentry C, Cotman CW (1980b) Loss and reacquisition of hippocampal synapses after selective destruction of CA3CA4 afferents with kainic acid. Brain Res 191:387-403.

Nakajima S, Franck JE, Bilkey D, Schwartzkroin PA (1991) Local circuit synaptic interactions between CAl pyramidal cells and interneurons in the kainate-lesioned hyperexcitable hippocampus. Hippocampus 1:67-78.

Phelps S, Mitchell J, Wheal HV (1991) Changes to synaptic ultrastructure in field CA1 of the rat hippocampus following intracerebroventricular injection of kainic acid. Neuroscience 40:687-699.

Pumain R (1981) Electrophysiological abnormalities in chronic epileptogenic foci: an intracellular study. Brain Res 219:445-450.

Radpour S, Thomson AM (1991) Local excitatory connexions between CA1 neurones in slices of rat hippocampus. J Physiol (Lond), in press.

Sayer RJ, Redman SJ, Andersen P (1989) Amplitude fluctuations in small EPSPs recorded from CAl pyramidal cells in the guinea pig hippocampal slice. J Neurosci 9:840-850.

Sayer RJ, Friedlander MJ, Redman SJ (1990) The time course and amplitude of EPSPs evoked at synapses between pairs of CA3/CA1 neurons in the hippocampal slice. J Neurosci 10:826-836.

Schwartzkroin PA, Knowles WD (1984) Intracellular study of human epileptic cortex: in vitro maintenance of epileptiform activity? Science 223:709-712.

Schwartzkroin PA, Wyler AR (1980) Mechanisms underlying epileptiform burst discharge. Ann Neurol 7:95-107.

Schwartzkroin PA, Turner DA, Knowles WD, Wyler AR (1983) Studies of human and monkey 'epileptic' neocortex in the 'in vitro' slice preparation. Ann Neurol 13:249-257.

Simpson LH, Wheal HV, Williamson R (1991) The contribution of non-NMDA and NMDA receptors to graded bursting activity in the CA1 region of the hippocampus in a chronic model of epilepsy. Can J Physiol Pharmacol, in press.

Sloviter RS (1987) Decreased hippocampal inhibition and a selective loss of interneurons in experimental epilepsy. Science 235:73-76.

Sloviter RS (1991) Permanently altered hippocampal structure, excitability and inhibition after experimental status epilepticus in the rat: the "dormant basket cell" hypothesis and its possible relevance to temporal lobe epilepsy. Hippocampus 1:41-66.

Thomson AM, Girdlestone D, West DC. (1988) Voltage-dependent currents prolong single-axon postsynaptic potentials in layer III pyramidal neurons in rat cortical slices. J Neurophysiol 60:1896-1907.

Turner DA (1988) Waveform and amplitude characteristics of evoked responses to dendritic stimulation of CA1 guinea-pig pyramidal cells. J Physiol (Lond) 395:419-439.

Turner DA (1990) Feed-forward inhibitory potentials and excitatory interactions in guinea-pig hippocampal pyramidal cells. J Physiol (Lond) 422:333-350.

Turner DA, Schlieckert M (1990) Data acquisition and analysis system for intracellular neuronal signals. J Neurosci Methods 35:241-251.

Turner DA, Wheal HV (1988) Components of subthreshold synaptic potentials in CA1 pyramidal neurones from kainic acid lesioned rat hippocampus in vitro. J Physiol (Lond) 400:50P.

Wheal HV (1989) Function of synapses in the CA1 region of the hippocampus: their contribution to the generation or control of epileptiform activity. Comp Biochem Physiol 93A:211-220. 
Wheal HV (1990) The plasticity of synapses in the CA1 area of the kainic acid lesioned hippocampus. Adv Exp Med Biol 268:461-470. Wheal HV, Turner DA (1988) Early and late EPSP components in CA1 pyramidal neurons from kainic acid lesioned rat hippocampus. Soc Neurosci Abstr 14:790.
Wheal HV, Ashwood TJ, Lancaster B (1984) A comparative in vitro study of the kainic acid lesioned and bicucilline treated hippocampus: chronic and acute models of focal epilepsy. In: Electrophysiology of epilepsy (Schwartzkroin PA, Wheal HV, eds), pp 173-200. New York: Academic. 